\title{
Non-Negligible Stack Emissions of Noncriteria Air Pollutants from Coal-Fired \\ Power Plants in China: Condensable Particulate Matter and Sulfur Trioxide
}

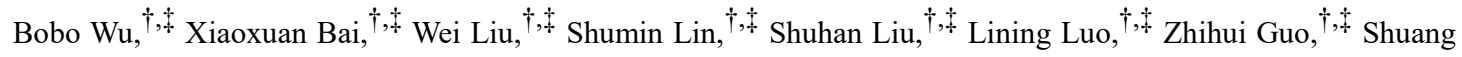

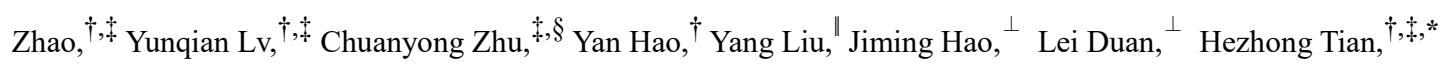

${ }^{\dagger}$ State Key Joint Laboratory of Environmental Simulation \& Pollution Control, School of Environment, Beijing Normal University, Beijing 100875, China

${ }^{\ddagger}$ Center for Atmospheric Environmental Studies, Beijing Normal University, Beijing 100875, China

${ }^{\S}$ School of Environmental Science and Engineering, Qilu University of Technology, Jinan 250353, China

" Rollins School of Public Health, Emory University, Atlanta 30322, Georgia, United States

${ }^{\perp}$ School of Environment, Tsinghua University, Beijing 100084, China

*Corresponding author: Dr. H.Z. Tian, E-mail: hztian@bnu.edu.cn

\section{Content:}

Number of pages: 5

Number of tables: 1

Number of figures: 5 


\section{Equations}

All the associated quantitative formulas of mass concentrations, removal efficiencies, and $6 \%$ oxygen content conversion are shown as follows:

$$
C_{\mathrm{SO}_{3}}=\frac{c \times V \times M_{\mathrm{SO}_{3}}}{Q \times M_{\mathrm{SO}_{4}{ }^{2-}}}
$$

where $\boldsymbol{C}_{\boldsymbol{S O}_{3}}$ is the mass concentration of $\mathrm{SO}_{3}, \mathrm{mg} / \mathrm{m}^{3} ; \boldsymbol{c}$ is the tested concentration of $\mathrm{SO}_{4}{ }^{2-}, \mathrm{mg} / \mathrm{L} ; \boldsymbol{V}$ is the sample volume, $\mathrm{L} ; \boldsymbol{Q}$ is the total volume of sampled flue gas, $\mathrm{m}^{3} ; \boldsymbol{M}_{\boldsymbol{S O}_{3}}$ and $\boldsymbol{M}_{\boldsymbol{S O}_{4}}{ }^{2-}$ are the molecular weights of $\mathrm{SO}_{3}$ and $\mathrm{SO}_{4}{ }^{2-}$, respectively.

$$
\eta_{i, j}=\frac{C_{i, j, i n}-C_{i, j, o u t}}{C_{i, j, i n}}
$$

where $\boldsymbol{\eta}_{\boldsymbol{i}, \boldsymbol{j}}$ is the removal efficiency of facilities $\boldsymbol{j}$ for pollutants $\boldsymbol{i} ; \boldsymbol{C}_{\boldsymbol{i}, \boldsymbol{j}, \boldsymbol{i n}}$ and $\boldsymbol{C}_{\boldsymbol{i}, \boldsymbol{j}, \text { out }}$ represent the concentrations of pollutants $\boldsymbol{i}$ at the inlet and outlet of facilities $\boldsymbol{j}$.

$$
C_{i}=C_{i}^{\prime} \frac{21-O_{2}}{21-O_{2}^{\prime}}
$$

where $\boldsymbol{C}_{\boldsymbol{i}}$ is the mass concentration of pollutants $\boldsymbol{i}$ based on $6 \% \mathrm{O}_{2}, \mathrm{mg} / \mathrm{Nm}^{3} ; \boldsymbol{C}_{\boldsymbol{i}}^{\prime}$ is mass concentrations of pollutants $\boldsymbol{i}$ based on field tests, $\mathrm{mg} / \mathrm{m}^{3} ; \boldsymbol{O}_{2}$ is the unity oxygen

\begin{tabular}{|c|c|c|c|c|c|c|}
\hline $\begin{array}{c}\text { CFPPs } \\
\text { No. }\end{array}$ & $\begin{array}{c}\text { boiler } \\
\text { type }\end{array}$ & $\begin{array}{c}\text { steam flow } \\
\text { rate }(\mathrm{t} / \mathrm{h})\end{array}$ & coal & $A_{a r}(\%)$ & $S_{t, a r}(\%)$ & APCDs \\
\hline$\# 1$ & $\mathrm{PC}$ & 200 & & $23.18 \pm 3.18$ & $0.76 \pm 0.13$ & $\mathrm{SCR}+\mathrm{ESP} \& \mathrm{FF}+\mathrm{WFGD}^{a}$ \\
\hline$\# 2$ & $\mathrm{PC}$ & 410 & bituminous & $26.15 \pm 2.99$ & $0.66 \pm 0.16$ & $\mathrm{SCR}+\mathrm{FF}+\mathrm{WFGD}^{a}$ \\
\hline$\# 3$ & CFB & 260 & coal & $24.92 \pm 6.05$ & $0.83 \pm 0.44$ & $\mathrm{SNCR}+\mathrm{FF}+\mathrm{WFGD}^{b} \& \mathrm{WESP}$ \\
\hline \#4 & $\mathrm{PC}$ & 2209 & & $28.95 \pm 0.67$ & $1.46 \pm 0.06$ & $\mathrm{SCR}+\mathrm{ESP}+\mathrm{WFGD}^{b} \& \mathrm{WESP}$ \\
\hline
\end{tabular}
content, $\% ; \boldsymbol{O}_{2}^{\prime}$ is the oxygen content in flue gas based on field test, $\%$.

Table S1. Information for the tested CFPPs and ash $\left(A_{a r}\right) /$ sulfur $\left(S_{t, a r}\right)$ contents in feed coal

Note: ${ }^{a}$, ammonia-based WFGD; ${ }^{b}$, limestone-based WFGD. 


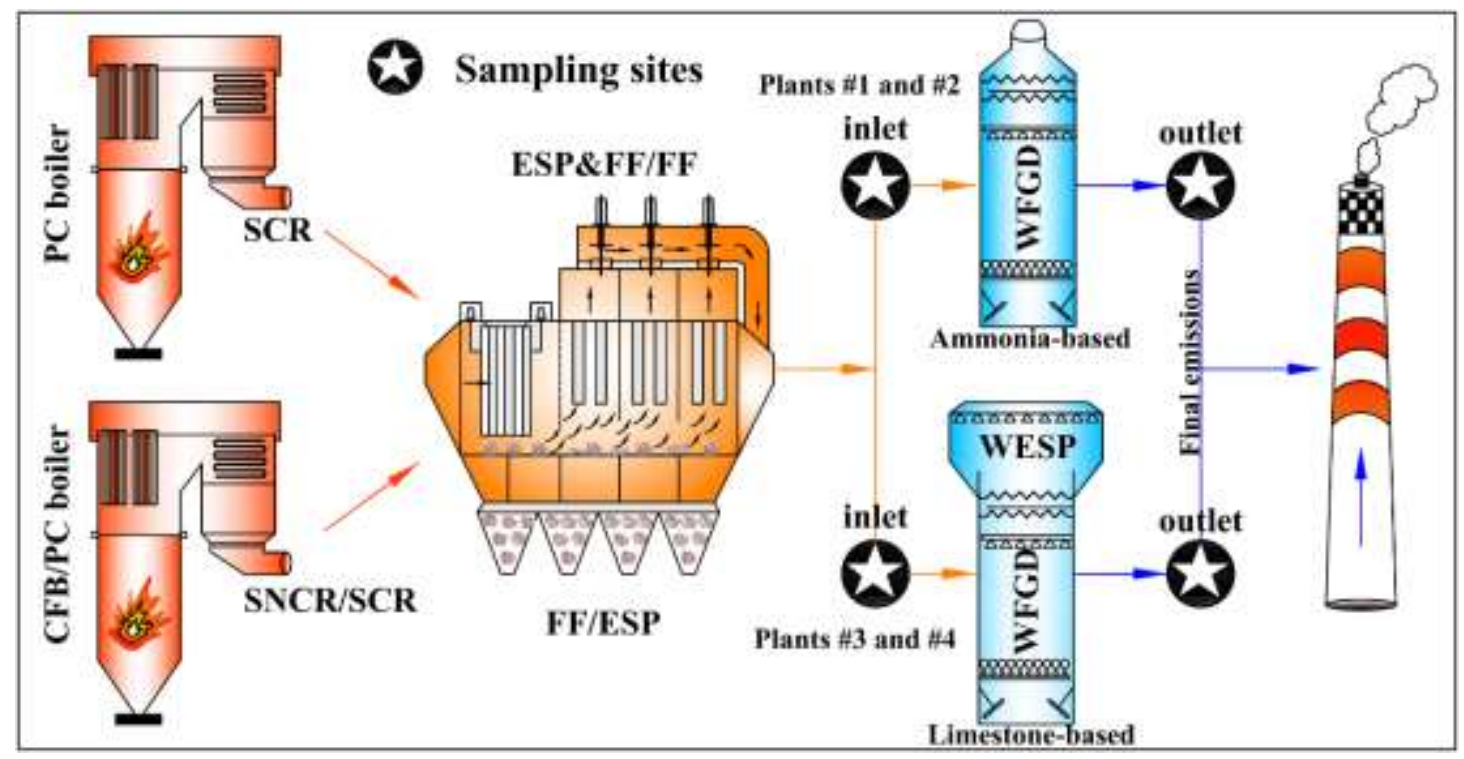

Figure S1. The schematic configuration of tested CFPPs and sampling sites
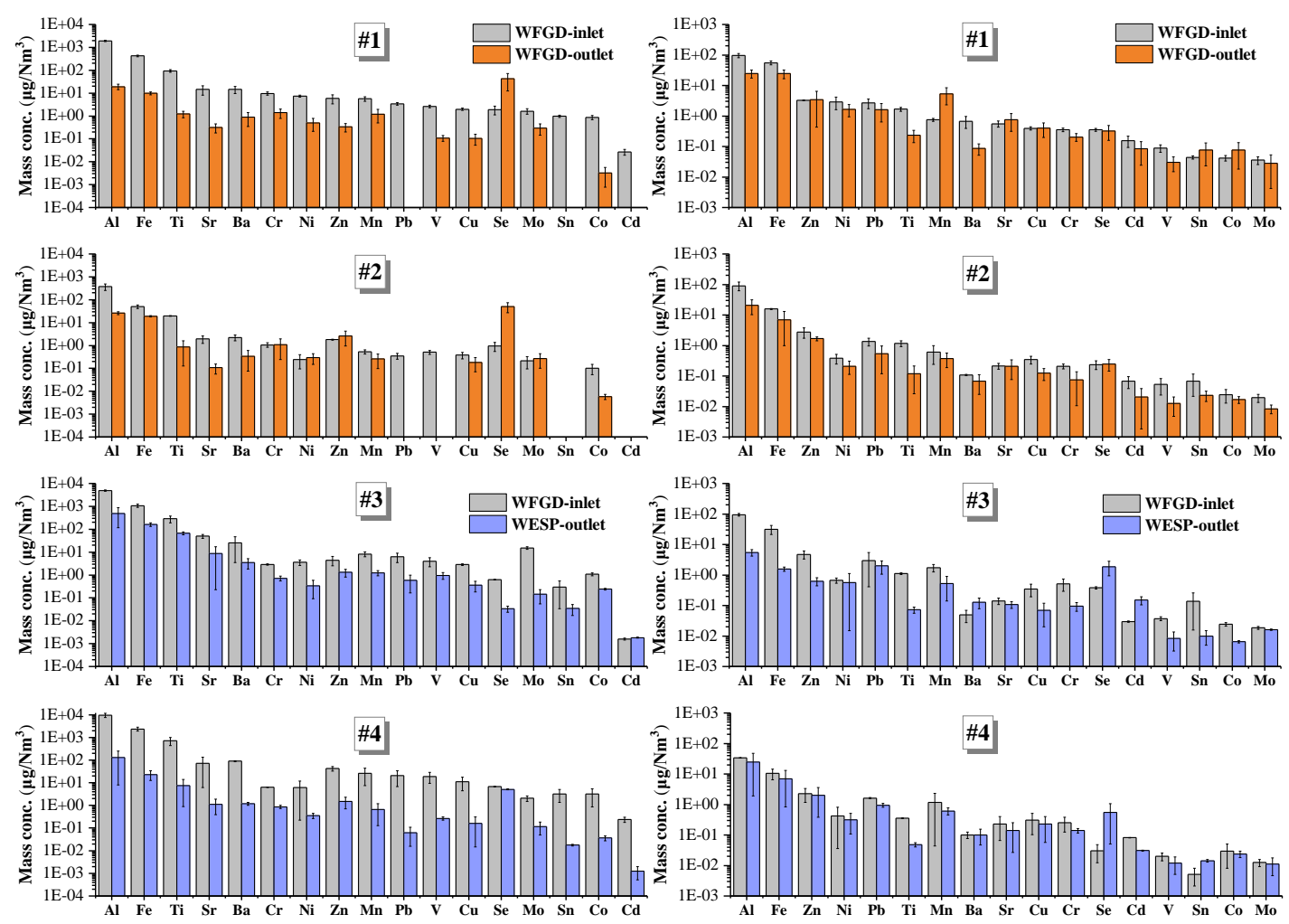

Elements in FPM

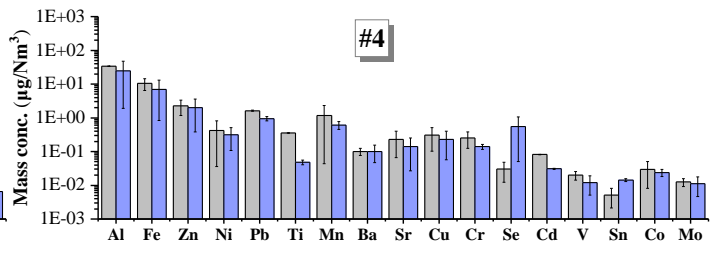

Elements in CPM

Figure S2. Mass concentrations $\left(\mu \mathrm{g} / \mathrm{Nm}^{3}\right)$ of elemental species in FPM and CPM at the tested sites 


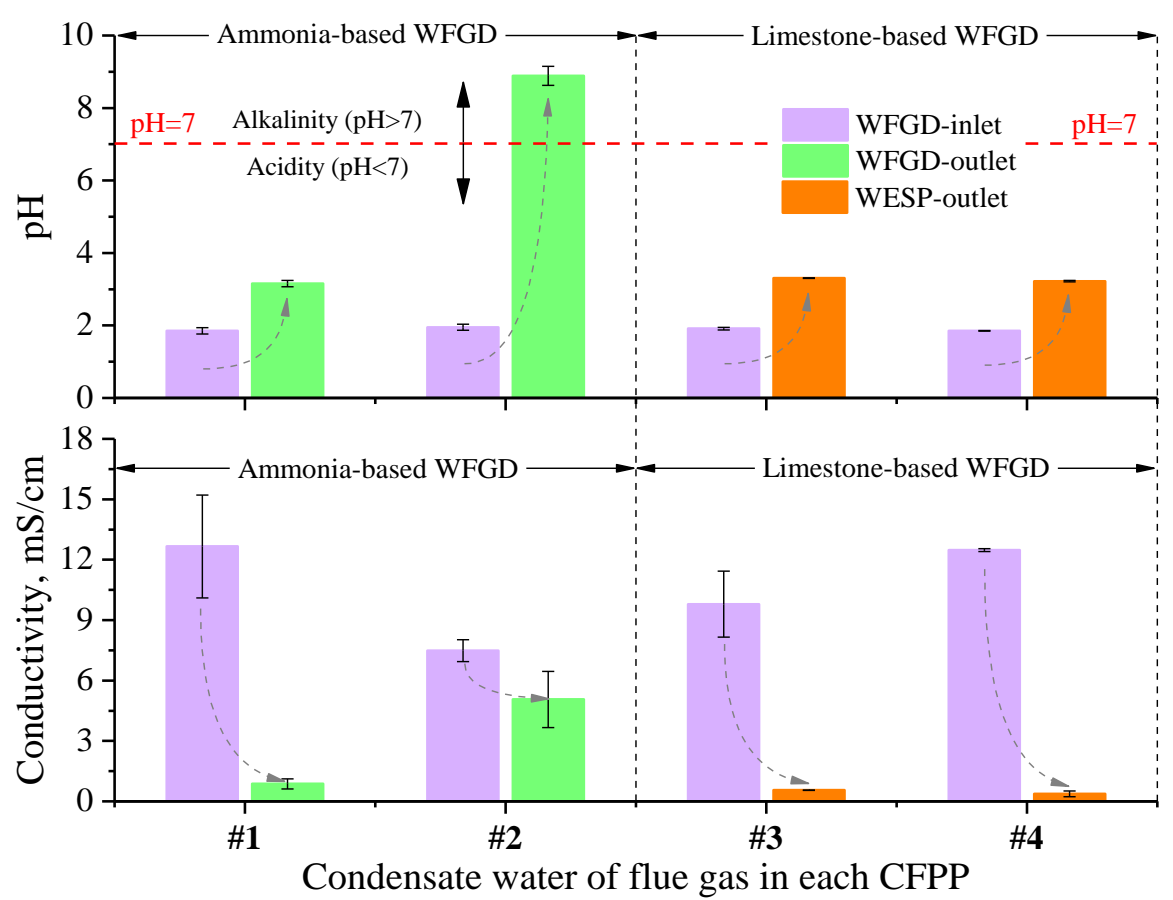

Figure S3. The $\mathrm{pH}$ and conductivity $(\mathrm{mS} / \mathrm{cm})$ of condensate water in flue gas for each tested CFPP

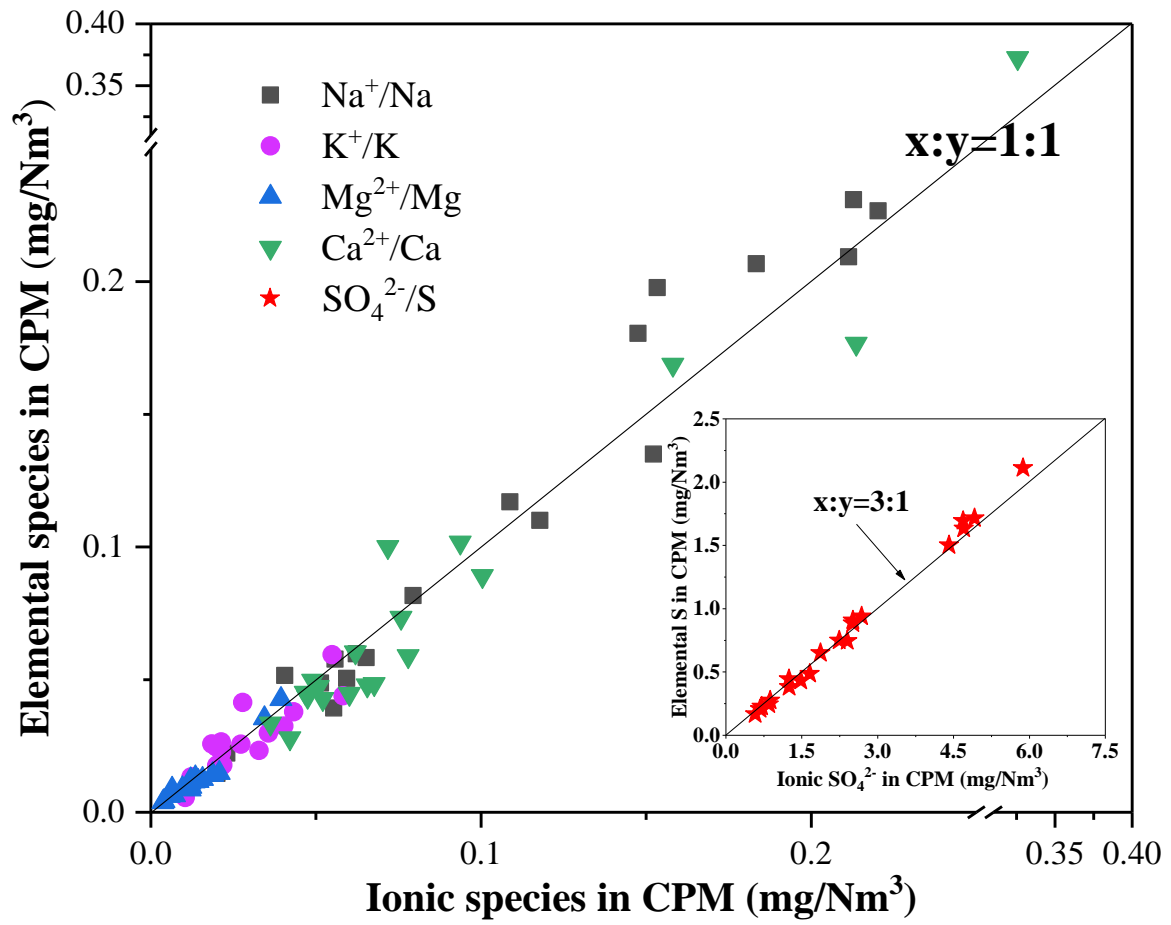

Figure S4. Mass concentrations $\left(\mathrm{mg} / \mathrm{Nm}^{3}\right)$ of some ionic and elemental species in CPM 


\section{S distribution in the stack emissions of CFPPs}

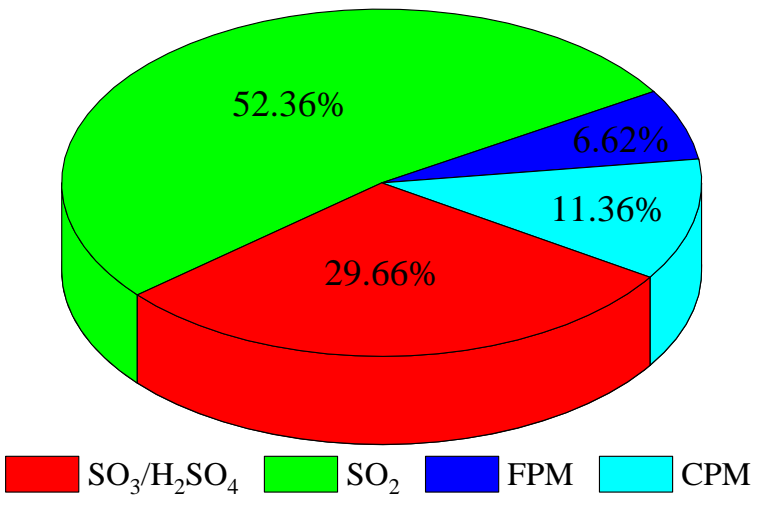

Figure S5. The proportions of $\mathrm{S}$ in $\mathrm{SO}_{3} / \mathrm{H}_{2} \mathrm{SO}_{4}, \mathrm{SO}_{2}, \mathrm{FPM}$, and CPM at the stack emissions 